\title{
Use of displacement as a proxy for dike safety
}

\author{
Elahe Jamalinia, Phil Vardon, and Susan Steele-Dunne
}

Faculty of Civil Engineering and Geosciences, Delft University of Technology, Delft, the Netherlands

Correspondence: Elahe Jamalinia (e.jamalinia@tudelft.nl)

Published: 22 April 2020

\begin{abstract}
Climatic conditions and vegetation cover influence water flux in a slope which affect the pore water pressure and self weight, hence its stability. High evapotranspiration and low precipitation rates during summer cause dry soil with low soil moisture (SM) that leads to soil shrinkage, which leads to cracking and reduced shear strength, which consequently decreases the stability of slopes. Soil re-wetting increases slope weight and exerts an additional driving force on the slope. Using Earth observation (EO) data facilitates frequent, large-scale monitoring to identify the vulnerable areas along the slopes to avoid instability. Here we study the displacement of a vegetated dike subject to SM variations under varying climatic conditions. Results show that the SM and magnitude of total displacement at a desired location are highly positively correlated without time lag. This proof-of-concept study shows that near surface displacement due to interaction with the atmosphere has a strong relation with the water availability in the slope and therefore the Factor of Safety (FoS).
\end{abstract}

\section{Introduction}

Dikes are predominantly earth structures, which form a large part of existing flood defence systems and their primary objective is to provide protection against flood events (CIRIA et al., 2013). Failures of flood defence systems often lead to significant losses. Natural or human-induced driving mechanisms can cause dike failures due to either hydraulic or geotechnical problems. The monitoring of these dikes is crucial in assessing safety and avoiding flooding events. In the Netherlands, dikes are inspected by a dike inspector walking the dike looking for irregularities (Givehchi et al., 2003). In recent studies, e.g. Cundill et al. (2013), Özer et al. (2019) and Jamalinia et al. (2019a), it has been proposed that Earth Observation (EO) can be a useful tool for increasing the efficiency, objectivity and coverage of dike inspection of vulnerable areas to be identified for detailed studies. Here, the displacement of an example vegetated dike under variable climatic conditions is studied, to investigate how measuring displacement would help dike managers detect vulnerable areas along dikes.

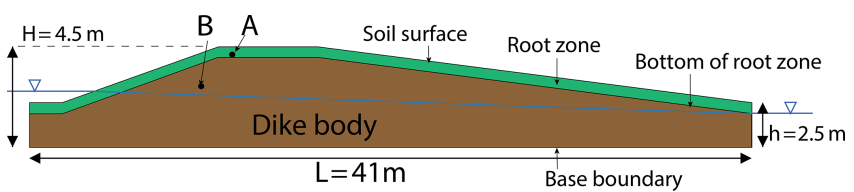

Figure 1. Geometry representing boundary, root zone layers, and points in which following results are plotted (after Jamalinia et al., 2019a).

\section{Method}

Both drainage and vegetation strongly affect dike performance (Vardon, 2015; Elia et al., 2017). As available geotechnical models cannot simulate the effect of vegetation on dike stability, in the current study, a crop growth model is coupled to a Finite Element Method (FEM) model to enable the evaluation of variable climatic and vegetation conditions on dike stability. Furthermore, these models are modified to simulate cracking. The modelling strategy is as follows: (1) A 1-D crop (grass) model, LINGRA (Bouman et al., 1996), is used to simulate the infiltration of water into and out of the root zone. This model uses weather data as input and simulates the evaporation, transpiration, water interception by the vegetation, drainage from the root zone layer and vegetation growth. LINGRA can account for growth in 
(a)

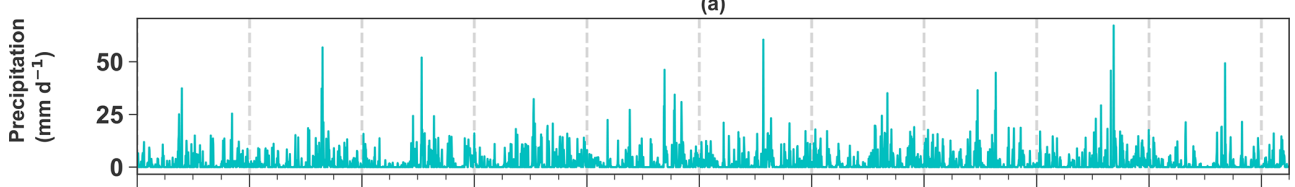

(b)

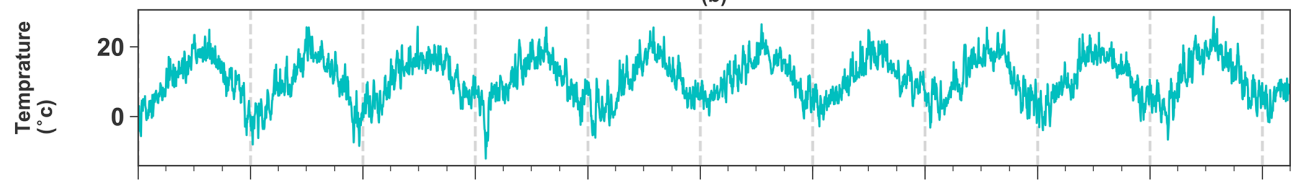

(c)

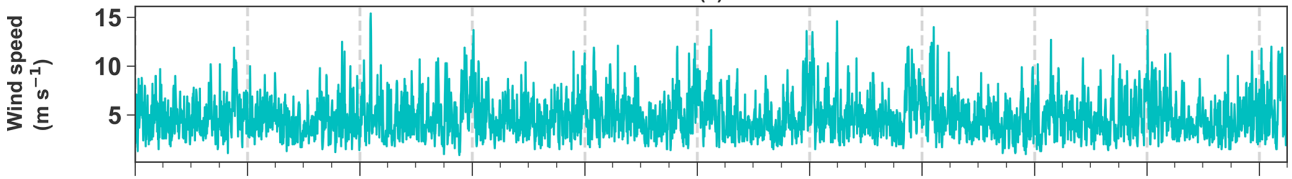

(d)

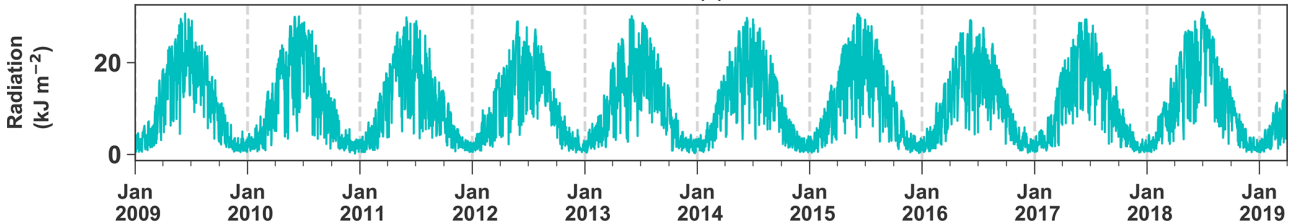

Figure 2. Daily values of inputs for the crop model from 2009 to 2019. (a) Precipitation; (b) radiation; (c) average temperature; (d) average wind speed.
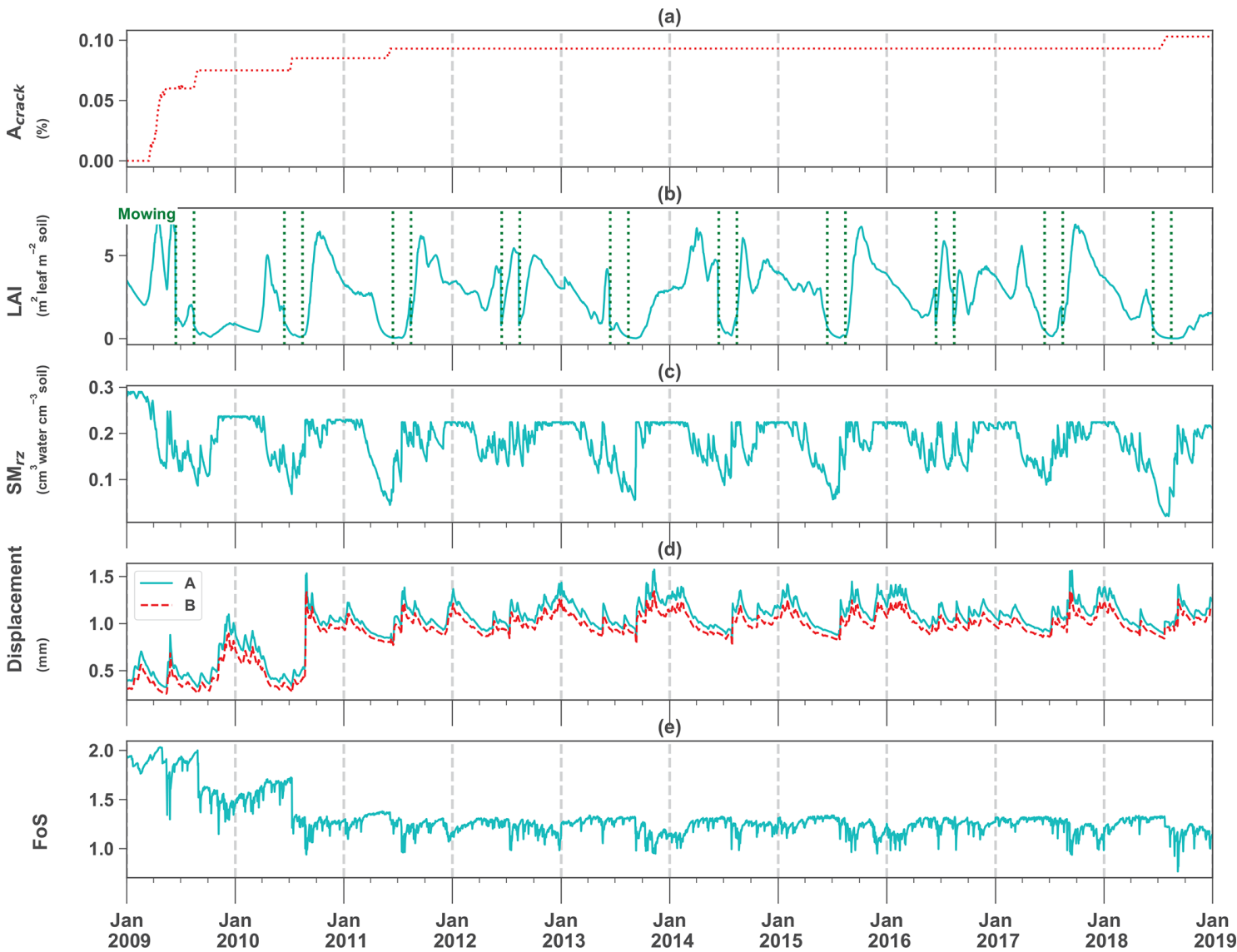

Figure 3. Daily values of selected outputs for two models from 2009 to 2019. (a) Crack area; (b) Leaf Area Index (LAI); (c) root zone soil moisture $\left(\mathrm{SM}_{\mathrm{rz}}\right)$; (d) displacement at locations A and B shown in Fig. 1; (e) Factor of Safety (FoS) (after Jamalinia et al., 2019b). 
2009-2018

(a)

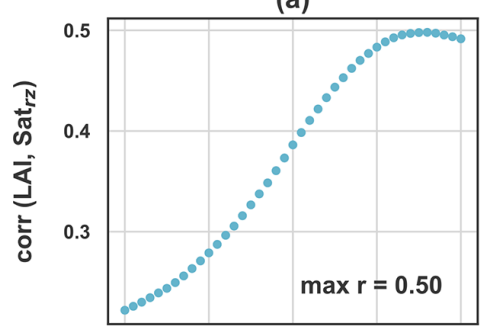

(d)

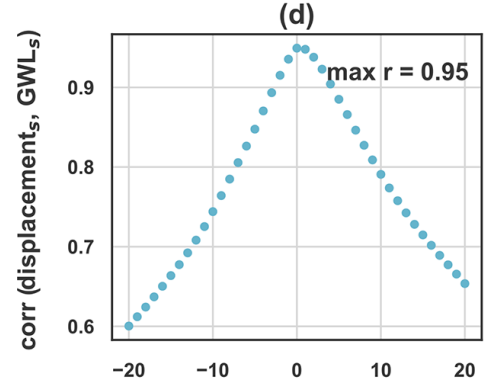

(b)

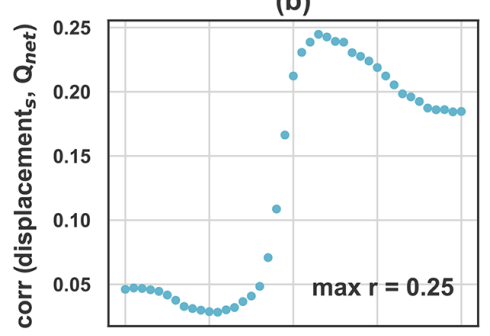

(e)

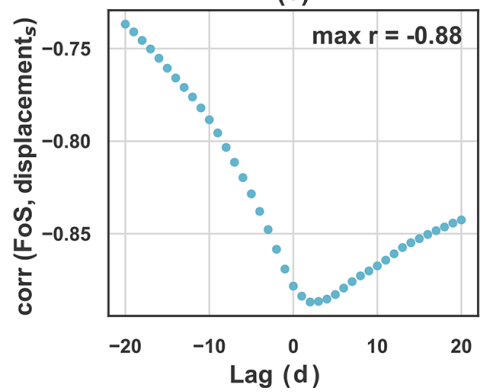

(c)

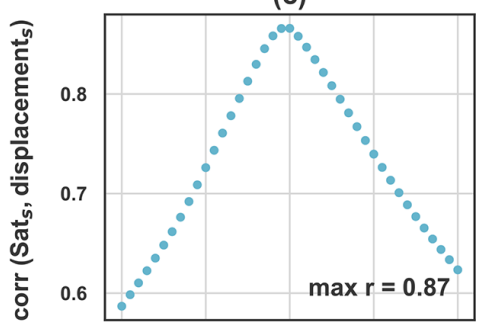

(f)

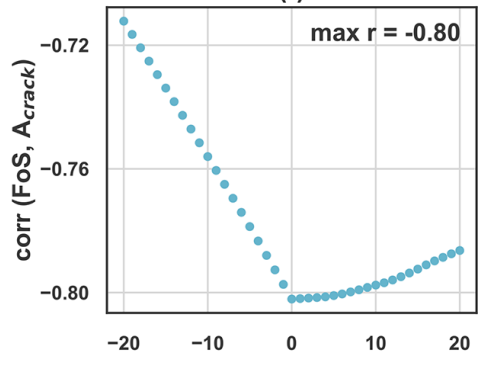

Figure 4. Correlation coefficient $(r)$ between two parameters with time lags between -20 and $20 \mathrm{~d}$ during ten years of simulation.

water-limited condition which is the case for the grass on dikes in the Netherlands. Here, LINGRA has been adopted to account for macropores. (2) A 1-D geotechnical model, PLAXIS (Plaxis BV, 2018), is used to simulate the hydraulic behaviour of the root zone, where only the calculated water in step (1) entering the root zone is applied as a top boundary condition. The hydraulic material properties of the root zone are optimised so that the drainage from the bottom of the root zone matches in both models. (3) A 2-D geotechnical model, is used to simulate the hydro-mechanical behaviour in time, including both the displacement and the Factor of Safety (FoS). Shear strength parameters are reduced in this step to simulate the effect of cracks in the dike; as the crack area increases, cohesion and friction angle decreases. The description of the models and workflow are described in detail in Jamalinia et al. (2019a, b). LINGRA solves the water balance in the root zone for the cracked soil. Some of the precipitation flows through cracks directly to the lower layer, while the remainder reaches the lower layers though the soil matrix. The dike geometry used in the numerical study is representative of a regional dike in Amsterdam, the Netherlands, studied in the Veenderij project (de Vries, 2012), which consists of the root zone and the soil of the dike body (Fig. 1). LINGRA uses meteorological data as input (Fig. 2). The simulation period considered in this study is from 2009 to 2019. These data were obtained from the Dutch national weather service website (KNMI) at Schipol.

\section{Results}

Temporal results from the crop model are shown in Fig. 3ac. It is assumed that the cracks cannot seal (close) during wet periods, and can only increase their opening or aperture during drier soil-moisture conditions than previously encountered. Usually the percentage of the soil surface area which is cracked increases from spring and summer and its area remains constant until the next dry period in summer. As the crack expands only in drier conditions than have been previously encountered, the time between cracking events gets longer as the analysis progresses. Temporal variations in Leaf Area Index (LAI), ratio of leaf area to ground area, are shown in Fig. 3b. The sudden decrease in LAI shows mowing events on 15 June and 15 August which were imposed in the crop model based on the mowing schedule for regional dikes in the Netherlands (Jamalinia et al., 2019a). The presence of cracks decreases the rate of LAI growth after mowing, because some precipitation drains directly to the lower soil layer via cracks leading to a reduction in the maximum stored water (seen in Fig. 3c). High levels of evapotranspiration during the summer reduce soil moisture in the root zone $\left(\mathrm{SM}_{\mathrm{rz}}\right)$. For example, in summer 2018 the root zone experienced the lowest $\mathrm{SM}_{\mathrm{rz}}$ in all 10 years of the simulation, which caused crack growth. Hence, vegetation could not easily regrow after mowing that summer. Temporal results from the 2-D geotechnical model are shown in Fig 3d-e. The absolute displacement of the points A and B (Fig. 3d) increase as the crack area grows, which depicts the effect of shrinkage behaviour in the root zone. These values are mostly influenced 


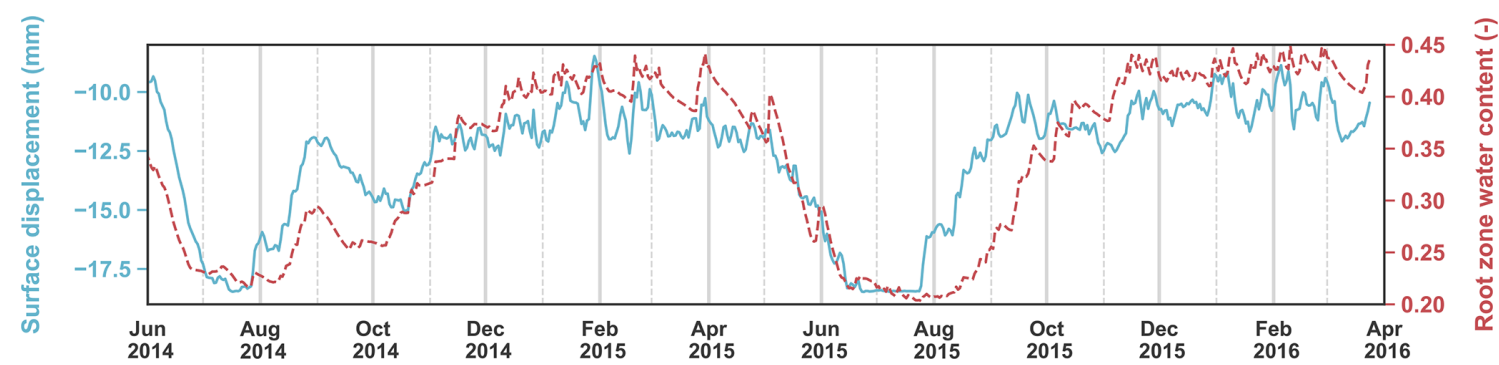

Figure 5. Time series of surface displacement and water content in the root zone (June 2014-April 2016).

(a)

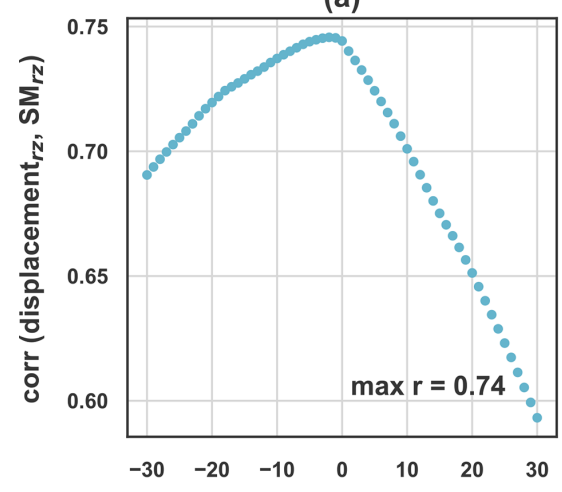

2012-2015

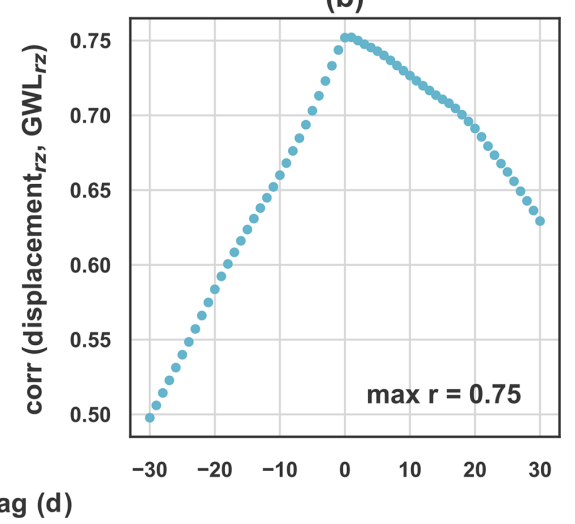

Figure 6. Correlation coefficient ( $r$ ) between: (a) displacement and SM, (b) displacement and GWL in the root zone with time lags as much as $30 \mathrm{~d}$ during 4 years at Veenderij dike.

by the displacement in the vertical direction, in a drier condition the soil settles more.

Temporal variation of Factor of Safety (FoS) is shown for the example dike (Fig. 3e). The FoS is responsive to the climate and vegetation condition. As cracks increase the FoS significantly decreases under the combined effect of more infiltration into the dike and lower shear strength induced by modified cohesion and friction angle. The maximum crack area leads to the minimum shear strength parameters, therefore lower FoS.

Correlation coefficients between pairs of key variables for the 10 years of the simulation are presented in Fig. 4. If the maximum absolute value of correlation occurs with a positive lag it means that the second term leads the first. In Fig. 4a, the peak correlation coefficient between LAI and root zone saturation $\left(\mathrm{Sat}_{\mathrm{rz}}\right)$, is obtained with two weeks lag. This reflects that the vegetation grows in response to water availability. In Fig. 4b a positive correlation between displacement and boundary net flux (effective precipitation minus evapotranspiration) is shown with maximum peak after $4 \mathrm{~d}$, that suggests that seasonal displacements are affected by climate and vegetation conditions. There is a strong positive correlation between the degree of saturation and displacement at the dike's surface (Fig. 4c), which shows that variation in $\mathrm{SM}_{\mathrm{rz}}$ leads to swelling/shrinkage behaviour of the soil causing sea- sonal near surface displacements on the same day. Therefore, having information of one of these two variables, the other can be estimated. The strong correlation between ground water level (GWL) and displacement at the surface proves the shallow displacement due to SM variations. There is a negative correlation between displacement at point A and safety of the dike (Fig. 4e), so knowing the displacement variation can inform dike managers regarding the safety condition. In Fig. 4f, it is shown that crack area increases is negatively correlated (with zero lag) to $\mathrm{FoS}$, as mentioned earlier regarding the time series results shown in Fig. 3.

The following in situ data are from a regional dike in Amsterdam, the Netherlands, studied in the Veenderij project (de Vries, 2012), and are analysed as a validation of the simulated behaviour.

Figure 5 shows the temporal variation of root zone water content and displacement for a nearly two-year period (June 2014-April 2016). The shallow displacement and root zone water content have the same temporal variations. Strong positive correlations between the SM and displacement, and between GWL and displacement in the root zone for four years (January 2012-January 2016) are shown in Fig. 6a-b. The magnitude of time lags of the correlation shown in Figs. 4 and 6 are comparable. 


\section{Use of displacement as an indicator for dike safety}

Meteorological and vegetation conditions influence the boundary net flux of water through the root zone and therefore available water in the dike. Seasonal changes in the surface displacement are strongly coupled to the moisture available in the root zone. Additionally, the strong correlation between displacement and FoS means that it is possible to utilise the displacement to monitor FoS. Currently, ground motion is monitored from satellites with millimeter precision. With a knowledge of the meteorological conditions, and surface displacement, vulnerable areas of the dike can be identified, and for detailed investigation the at-risk dike location can be investigated in more detail.

Data availability. The field data are not publicly available due to commercial restrictions.

Author contributions. EJ contributed in conceptualization, methodology, numerical simulation, data analysis, writing Original draft preparation, visualization, and investigation. PV and SSD contributed in supervision, writing - reviewing and editing.

Competing interests. The authors declare that they have no conflict of interest.

Special issue statement. This article is part of the special issue "TISOLS: the Tenth International Symposium On Land Subsidence - living with subsidence". It is a result of the Tenth International Symposium on Land Subsidence, Delft, the Netherlands, 17-21 May 2021.

Acknowledgements. This work is part of the research program Reliable Dikes with project number 13864 . We gratefully acknowledge Waternet for providing field data.

Financial support. This research has been supported by the Nederlandse Organisatie voor Wetenschappelijk Onderzoek (grant no. 13864).

\section{References}

Bouman, B. A. M., Schapendonk, A. H. C. M., Stol, W., and Van Kraalingen, D. W. G.: Description of LINGRA, a model approach to evaluate potential productivities of grasslands in different European climate regions, Quantitative Approaches in System Analysis, 7, 11-58, 1996.

CIRIA (Construction Industry Research and Information Association), MEDE (Ministère de l'Ecologie du Développement durable et de l'Energie) and USACE (US Army Corps of Engineers): The International Levee Handbook, CIRIA, London, UK, 2013.

Cundill, S. L., Hack, H. R. G. K., van der Meijde, M., van der Schrier, J. S., and Ngan-Tillard, D. J. M.: Potential of Using Remote Sensing Data for Dike Inspection, in: New Frontiers in Engineering Geology and the Environment, edited by: Huang, Y., Wu, F., Shi, Z., and Ye, B., Springer Berlin Heidelberg, Berlin, Heidelberg, Germany, 203-206, 2013.

de Vries, G.: Monitoring droogteonderzoek veenkaden, Tech. rep., Deltares, Delft, the Netherlands, 2012.

Elia, G., Cotecchia, F., Pedone, G., Vaunat, J., Vardon, P. J., Pereira, C., Springman, S. M., Rouainia, M., Van Esch, J., Koda, E., Josifovski, J., Nocilla, A., Askarinejad, A., Stirling, R., Helm, P., Lollino, P., and Osinski, P.: Numerical modelling of slopevegetation-atmosphere interaction: an overview, Q. J. Eng. Geol. Hydroge., 50, 249-270, 2017.

Givehchi, M., Vrijling, J., Hartmann, A., Gelder, P., and Van Baars, S.: Application of remotely sensed data for detection of seepage in dikes, Int. Arch. Photogramm. Remote Sens. Spatial Inf. Sci., 34, 378-382, 2003.

Jamalinia, E., Vardon, P. J., and Steele-Dunne, S. C.: The effect of soil-vegetation-atmosphere interaction on slope stability: a numerical study, Environmental Geotechnics, https://doi.org/10.1680/jenge.18.00201, ahead of print, 2019a.

Jamalinia, E., Vardon, P. J., and Steele-Dunne, S. C.: The impact of evaporation induced cracks and precipitation on temporal slope stability, Comput. Geotech., ahead of print, 2019b.

Özer, I. E., Rikkert, S. J., van Leijen, F. J., Jonkman, S. N., and Hanssen, R. F.: Sub-seasonal levee deformation observed using satellite radar interferometry to enhance flood protection, Sci. Rep., 9, 2646, https://doi.org/10.1038/s41598-019-39474-x, 2019.

Plaxis BV: PLAXIS Reference Manual 2018, Tech. rep., Delft, the Netherlands, 2018.

Vardon, P. J.: Climatic influence on geotechnical infrastructure: a review, Environmental Geotechnics, 2, 166-174, https://doi.org/10.1680/envgeo.13.00055, 2015. 